\title{
Evaluating Microbial Safety of Slow Partial-Cooking Processes for Bacon: Use of a Predictive Tool Based on Small-Scale Isothermal Meat Inoculation Studies
}

\author{
GREG M. BURNHAM, MELODY A. FANSLAU, AND STEVEN C. INGHAM* \\ University of Wisconsin-Madison, Department of Food Science, 1605 Linden Drive, Madison, Wisconsin 53706, USA
}

MS 05-271: Received 31 May 2005/Accepted 2 October 2005

\begin{abstract}
The objective of this study was to develop a predictive tool for evaluating the safety of slow cooking of pork products and identifying associated critical limits. Small-scale ( $25 \mathrm{~g})$ ground pork isothermal inoculation studies were done to determine Salmonella serovars, Escherichia coli O157:H7, and Staphylococcus aureus estimated critical times (time until growth reached a predefined increase of concern). Estimated critical time values ranged from $720 \mathrm{~min}$ at $21^{\circ} \mathrm{C}\left(\mathrm{S}\right.$. aureus) to $120 \mathrm{~min}$ at $40.6^{\circ} \mathrm{C}$ (E. coli $\mathrm{O} 157: \mathrm{H} 7)$ and were used to develop a multiple-temperature-interval predictive tool for non-isothermal processes. To test predictions, cured-pumped pork bellies were inoculated with Salmonella serovars, E. coli O157:H7, and S. aureus, subjected to slow partial cooking, and quantitatively analyzed for pathogens. Processes lasted 6 to $18 \mathrm{~h}$, with the product interior temperature within the 21 to $46^{\circ} \mathrm{C}$ range for 263 to $1080 \mathrm{~min}$ (high-humidity processes) and 217 to 921 min (low-humidity processes). Growth of Salmonella serovars $(>0.3 \mathrm{log})$, E. coli O157:H7 $(>0.3 \mathrm{log})$, and S. aureus $(>1.3 \mathrm{log})$ in the pork belly interior was predicted for 10, 14, and 5 of 18 trials, respectively. The tool was fail-safe, because pathogen growth, relative to time zero, did not occur anytime regardless of whether it was predicted. For the pork belly surface, the tool performed similarly. Estimated critical time values obtained by fitting the Baranyi equation to isothermal experiment data were also determined and, if used in the predictive tool, would result in even more conservative predictions. Our study substantiates the safety of the tested bacon slow partial-cooking processes and the potential usefulness of our isothermal-based tool in process safety evaluation.
\end{abstract}

Under the "Pathogen Reduction; Hazard Analysis and Critical Control Point (HACCP) Systems: Final Rule" of 1996 (12), meat processors were required to implement the HACCP system as their main food safety program. Since 2000, all wholesale meat processors have had a HACCP system in place. An important part of the HACCP system is the use of scientifically validated critical limits at critical control points that control significant hazards identified by the processor. For the critical control point of cooking, the Food Safety and Inspection Service of the U.S. Department of Agriculture (USDA) provided critical limit guidance (Appendix A, "Compliance Guidelines for Meeting Lethality Performance Standards for Certain Meat and Poultry Products") (13) that cautions processors against using slowcooking processes in which the product interior temperature increases from 10 to $54.4^{\circ} \mathrm{C}$ in $>6 \mathrm{~h}$. Although such processes are not forbidden, the onus of establishing their safety, along with scientifically valid critical limits that assure product safety, rests with the processor. The concerns associated with slow cooking are excessive growth of infective pathogens (such that subsequent cooking is insufficient to ensure safety) and the production of heat-stable enterotoxin by Staphylococcus aureus. Ideally, slow-cooking critical limit validation would be based on experimental pathogen challenge studies with the processor's products. This

\footnotetext{
* Author for correspondence. Tel: 608-265-4801; Fax: 608-262-6872;
}

E-mail: scingham@wisc.edu. is a costly endeavor, however, and not economically feasible for small and very small processors (11). In addition, pathogen challenge studies cannot be done in a commercial meat plant. Developing acceptable, lower-cost, alternative validation strategies has been an industry challenge.

One method to validate slow-cooking critical limits would be to analyze processing parameters using computergenerated predictive models of pathogen growth or survival. For example, growth of pathogens in a non-isothermal slow-cooking process can be predicted by dividing the process into multiple small temperature-change intervals, using the USDA Pathogen Modeling Program (PMP 7.0; Agricultural Research Service, Eastern Regional Research Center, Wyndmoor, Pa.) to predict growth in each interval, and then summing the predictions. It has been our experience in applying the PMP this way that the PMP may prove to be overly conservative when specific product parameters are not incorporated into the model. Furthermore, USDA regulators do not generally accept predictive model results as the sole means of critical limit validation (14). Another limitation of the PMP is that it is based on isothermal growth conditions in laboratory media and not in an actual meat product. A low-cost alternative to pathogen challenge studies, which may overcome the above limitations, is to use a combination of (i) in-plant data on survival/growth of indigenous microbes (e.g., aerobic plate count and indicator organisms such as coliforms) that may mirror path- 
TABLE 1. Pathogen strains used for isothermal and challenge studies

\begin{tabular}{|c|c|c|c|}
\hline Species & Strain no. & Isolated from & Source \\
\hline E. coli $\mathrm{O} 157: \mathrm{H7}$ & ATCC 43894 & Clinical sample & $\begin{array}{l}\text { American Type Culture Collection, } \\
\text { Manassas, Va. }\end{array}$ \\
\hline E. coli $\mathrm{O} 157: \mathrm{H} 7$ & ATCC 43895 & $\begin{array}{l}\text { Ground beef implicated in } \\
\text { illness outbreak }\end{array}$ & American Type Culture Collection \\
\hline E. coli $\mathrm{O} 157: \mathrm{H} 7$ & ATCC 51657 & Clinical sample & American Type Culture Collection \\
\hline E. coli $\mathrm{O} 157: \mathrm{H} 7$ & ATCC 51658 & Clinical sample & American Type Culture Collection \\
\hline Salmonella Typhimurium & S9 & $\begin{array}{c}\text { Clinical sample, Wisconsin } \\
\text { Laboratory of Hygiene }\end{array}$ & $\begin{array}{l}\text { Dr. Eric Johnson, Food Research In- } \\
\text { stitute, University of Wisconsin- } \\
\text { Madison }\end{array}$ \\
\hline Salmonella Heidelberg & $\mathrm{S} 13$ & $\begin{array}{l}\text { Clinical sample, Wisconsin } \\
\text { Laboratory of Hygiene }\end{array}$ & Dr. Eric Johnson \\
\hline Staphylococcus aureus & ATCC 12600 & Clinical sample & American Type Culture Collection \\
\hline S. aureus & ATCC 25923 & Clinical sample & American Type Culture Collection \\
\hline S. aureus & FRI-100 & $\begin{array}{l}\text { Cake implicated in illness } \\
\text { outbreak }\end{array}$ & $\begin{array}{l}\text { Dr. Amy Wong, Food Research Insti- } \\
\text { tute, University of Wisconsin- } \\
\text { Madison }\end{array}$ \\
\hline S. aureus & FRI-472 & $\begin{array}{l}\text { Turkey salad implicated in } \\
\text { illness outbreak }\end{array}$ & Dr. Amy Wong \\
\hline S. aureus & FRI-1007 & $\begin{array}{l}\text { Genoa salami implicated in } \\
\text { illness outbreak }\end{array}$ & Dr. Amy Wong \\
\hline
\end{tabular}

ogen behavior; (ii) growth predictions from a tool based on studies using actual meat products (rather than laboratory media); and (iii) citations of relevant pathogen challenge studies conducted in laboratories. This combined approach to critical limit validation is more likely to be accepted by industry regulators.

In this study, we intended to provide two of these types of information for processors to use in validating critical limits for slow-cooking procedures. Our first objective was to develop a predictive tool for pathogen growth during slow partial cooking of pork products using lag times experimentally determined in isothermal studies using ground pork. Our second objective was to conduct pathogen challenge studies of the slow partial cooking of bacon, determine process safety based on experimental data, and compare the experimental data to safety predictions derived from our tool and those made using values derived from USDA's PMP to establish potential associated critical limits.

\section{MATERIALS AND METHODS}

Inocula preparation. Five strains each of Escherichia coli O157:H7, Salmonella serovars, and S. aureus, prepared from frozen stock culture, were used (Table 1). To obtain a working culture, each strain was cultured twice successively at $35^{\circ} \mathrm{C}$ for 18 to $24 \mathrm{~h}$ in brain heart infusion broth (Difco, Becton Dickinson, Sparks, Md.), streaked to brain heart infusion agar (Difco), incubated at $35^{\circ} \mathrm{C}$ for 18 to $24 \mathrm{~h}$, examined for purity, and then stored at $5^{\circ} \mathrm{C}$. Because the raw ground pork and pumped-cured pork bel- lies were refrigerated, indigenous pathogens were unlikely to be multiplying; therefore, stationary-phase cultures were used for inoculation. To achieve stationary-phase inoculum cultures, an isolated colony of each strain was transferred from its working culture plate to $9 \mathrm{ml}$ of brain heart infusion broth, and then incubated at $35^{\circ} \mathrm{C}$ for $24 \mathrm{~h}$. Inocula were prepared for each pathogen by combining each of the five cultured strains into a 50-ml centrifuge tube (Falcon Brand, Fisher Scientific, Itasca, Ill.) and centrifuging at $5,000 \times g$ for $12 \mathrm{~min}$. Supernatant was decanted, and the pellet was resuspended to $25 \mathrm{ml}$ using Butterfield's phosphate diluent (BPD; Nelson Jameson, Marshfield, Wis.). From the three separate (5-strain) pathogen cocktails, $10 \mathrm{ml}$ of each were then all combined into another 50-ml centrifuge tube, creating a 15-strain, three-pathogen cocktail. A 5-log CFU/g concentration for inoculated pork was used to allow for easy detection of either pathogen growth or death during the slow partial-cooking process, so $1 \mathrm{ml}$ was then transferred to $99 \mathrm{ml}$ of BPD to make the final inoculum. Three concurrent trials were conducted for each experimental temperature in the isothermal studies and three nonconcurrent trials were done for the bacon partial-cooking challenge studies. Separate inocula were prepared for each trial as described above.

Isothermal studies. For the isothermal studies, fresh ground pork, free of ingredients such as spice, salt, and cure that may retard bacterial growth, was used. In this way, we intended to create a conservative tool, relative to pathogen growth in processed products such as bacon, ham, and sausage, which would predict the shortest pathogen growth times. Fresh boneless pork loin roasts were obtained from a local retail store and transported to the laboratory within $15 \mathrm{~min}$ and stored at $5^{\circ} \mathrm{C}$ until processed, or frozen at $-20^{\circ} \mathrm{C}$ until thawing at $5^{\circ} \mathrm{C}$ for use. Raw pork roasts 
were ground once using a meat grinder (UNIVEX brand, model MG8912, Salem, N.H.) with a grinding plate with 4-mm-diameter holes. Ground raw pork (ca. $25 \mathrm{~g}$ ) was packed into 50-ml centrifuge tubes to the 25-ml line on the tube. Once the pork was packed in the tube, a hole, 3 to $4 \mathrm{~mm}$ in diameter, was placed in the center of the pork using a sterile bent plastic spreader (Daigger, Vernon Hills, Ill.) to a depth of $2 \mathrm{~cm}$ for inoculation. Isothermal studies were conducted at $2.8^{\circ} \mathrm{C}\left(5^{\circ} \mathrm{F}\right)$ intervals ranging from 21 to $49^{\circ} \mathrm{C}$ ( 70 to $\left.120^{\circ} \mathrm{F}\right)$. Samplings were at time zero and hourly thereafter. Meat-packed centrifuge tubes (one tube for each of three concurrent trials/number of sampling times) were allowed to reach temperature equilibrium with the test temperature in a static water bath or an incubator (for $21^{\circ} \mathrm{C}$ ). A thermocouple (K-type, Dickson, Inc., Addison, Ill.) in the center of the meat was used to determine when the test temperature had been reached, whereupon each sample was inoculated in the hole created in the center of the meat mass with $100 \mu \mathrm{l}$ of the pathogen cocktail, and then reincubated and sampled accordingly for pathogen growth. For each sampling time, each of three tubes (one per trial) was analyzed by aseptically removing the contents of the tube into a filter sampling bag (NASCO Brand, Fisher Scientific, Itasca, Ill.), suspending with $99 \mathrm{ml}$ of BPD and stomaching at normal speed for 30 s using a Stomacher 400 (Seward, Fisher Scientific, Itasca, Ill.). The sample was then appropriately diluted in BPD and plated on selective media as described below.

Slow partial cooking of bacon challenge study. Raw, cured-pumped pork bellies were shipped by express courier from a local processor, received at approximately $5^{\circ} \mathrm{C}$ and stored $<3$ days until used. The pork bellies had been pumped with a cure solution resulting in an $11 \%$ increase in weight. The solution was composed of a $25 \%$ (wt/vol) sodium chloride solution $(60 \%$ [vol/ vol] of cure solution), water (22\%), sugar (11.5\% [wt/vol]), smoke flavor $(4.5 \%)$, sodium nitrite and other salts $(1.75 \%)$, and other proprietary ingredients $(0.25 \%)$. Analysis of the pork bellies by a commercial laboratory indicated an average composition of $46.9 \%$ moisture and $1.6 \%$ salt $(3.4 \%$ water-phase salt). Bellies were trimmed and halved; the medial surface was then scored to create a $5 \times 4$ grid of 20 sample areas of approximately $5 \mathrm{~cm}^{2}$ each. Belly thickness varied from 2.5 to $5.5 \mathrm{~cm}$. Because pork bellies are a whole-muscle product, pathogen contamination is most likely to occur at discrete locations via contact with a contaminated surface, e.g., injection needle, equipment, or another pork belly. To create an internal inoculation site, 12 of the sample areas were pierced ( 3 to $4 \mathrm{~mm}$ in diameter) to the middle of the belly thickness using a sterile bent plastic spreader. The remaining eight sample areas were used for surface inoculation. After pork belly preparation, sample areas were immediately inoculated with 100 $\mu l$ of the pathogen cocktail. Exterior (surface) sample areas were inoculated by depositing the inoculum and spreading it over the surface area using a sterile bent plastic spreader. Interior sample areas were inoculated by injecting the inoculum into the internal inoculation site. After inoculation, bellies were held for $30 \mathrm{~min}$ at $22^{\circ} \mathrm{C}$ to allow attachment. Then the bellies were subjected to a $6-$ $\mathrm{h}$ slow-cooking process intended to mimic the source manufacturer's procedure as well as extensions of this process resulting in process times of 12 and $18 \mathrm{~h}$. Simultaneous studies were conducted using cooking chambers with different air exchange levels. To simulate a high-humidity-no air exchange condition, an incubator (model 51221089, Precision, Inc., Winchester, Va.) was used. For a low-humidity-complete air exchange (air exhaust rate at approximately $0.8 \mathrm{~m} / \mathrm{s}$ ) condition, a food dehydrator (Pragotrade model TS160, Cabela's, Sidney, Nebr.) was used. Product and chamber temperatures as well as chamber percent relative humid- ity were monitored using data loggers (models SP150, TR320, and TM325; Dickson, Addison, Ill.). Sampling times for the bellies were at time zero for all processes and at 2, 4, and $6 \mathrm{~h}$ for 6 $\mathrm{h}$ processes, at 6,9 , and $12 \mathrm{~h}$ for 12 -h processes, and at 12, 15, and $18 \mathrm{~h}$ for 18 -h processes. Interior-inoculated and exterior-inoculated samples were obtained by excising the entire $5-\mathrm{cm}^{2}$ sample area. Two exterior and three interior samples were analyzed at each sampling time. Each sample was placed in a filter sampling bag, suspended in $99 \mathrm{ml}$ of BPD, and stomached at normal speed for $120 \mathrm{~s}$. Each sample was then appropriately diluted with BPD and plated on selective media as described below. The log CFU per gram data from the challenge study were statistically analyzed as described below for the isothermal studies. This analysis was done for each combination of inoculation site (pork belly surface or interior) and cooking conditions (high humidity-no air exchange or low humidity-complete air exchange) for each pathogen species.

Pathogen enumeration and confirmation. For each sampling time, trial, and inoculum organism, spread plates were prepared using a series of at least two and up to six decimal dilutions. For the initial homogenate, three plates were used and $1 \mathrm{ml}$ of sample was distributed (approximately 0.3, 0.3, and $0.4 \mathrm{ml}$ ) over all three plates and spread using a sterile bent plastic spreader. For all other dilutions, one plate was used and $100 \mu \mathrm{l}$ of appropriately diluted sample was spread using a sterile bent plastic spreader. The selective medium used for E. coli $\mathrm{O} 157: \mathrm{H} 7$ was sorbitol MacConkey agar (SMAC; Difco) on which typical colonies are opaque (colorless to white); atypical colonies are opaque (colorless to light pink) with no defined pink (to red) center. The selective medium used for Salmonella serovars was XLD agar (Oxoid, Ogdensburg, N.Y.) on which typical colonies have a black center and a well-defined clear to opaque (colorless to white) halo; atypical colonies have a less-defined black center. The selective medium used for $S$. aureus was Baird-Parker agar base (B-P; Difco) with tellurite egg yolk supplement (Difco). Typical colonies are shiny black with a distinctive clear zone in the surrounding agar. Atypical colonies do not have a well-defined clear zone. Both typical and atypical colonies on all media were counted. The SMAC and XLD plates were incubated at $35^{\circ} \mathrm{C}$ for $24 \mathrm{~h}$, while the B-P plates were incubated at $35^{\circ} \mathrm{C}$ for $48 \mathrm{~h}$. For the isothermal studies, confirmation tests of one colony of each pathogen per trial were conducted after enumeration. Gram stain reaction and colony morphology were observed for all organisms as well as catalase and latex agglutination (Oxoid) for S. aureus (resulting in $100 \%$ confirmed), oxidase (DrySlide kit; Fisher) and API 20E biochemical characterization (bioMerieux, Hazelwood, Mo.) for Salmonella serovars (resulting in $100 \%$ confirmed), and oxidase and latex agglutination (Oxoid) for E. coli O157:H7 (resulting in $100 \%$ confirmed). For the challenge studies, confirmation tests of one colony of each pathogen per trial were conducted after enumeration, with a $100 \%$ confirmation rate for $S$. aureus and E. coli O157:H7, and a 96\% rate for Salmonella serovars.

Data analysis and predictive tool development. An increase of concern (IC) was defined for each pathogen species. For the infective pathogens, Salmonella serovars and E. coli O157: $\mathrm{H} 7$, IC was defined as the time at which a $0.3 \log \mathrm{CFU}$ increase in population had occurred relative to starting concentration. Because $S$. aureus is only a significant hazard under conditions allowing growth to high levels, therefore producing enough enterotoxin to cause illness (7), IC for this pathogen was defined as the time until a $1.3 \log \mathrm{CFU}$ increase in population had occurred relative to starting concentration. Data from the isothermal studies were evaluated to determine the estimated critical time (ECT) at 
TABLE 2. Estimated critical times (ECT $=$ minutes for the first sampling time at which Escherichia coli O157:H7 or Salmonella serovars growth increased by $\log C F U>0.3$ or Staphylococcus aureus growth increased by $\log C F U>1.3$ ) in ground pork during isothermal incubation

\section{$\mathrm{ECT}^{a}$}

\begin{tabular}{rccc}
\cline { 2 - 4 } $\begin{array}{c}\text { Temp } \\
\left({ }^{\circ} \mathrm{F} /{ }^{\circ} \mathrm{C}\right)\end{array}$ & $\begin{array}{c}\text { E. coli O157:H7 } \\
\text { (IBT/DMFit) }\end{array}$ & $\begin{array}{c}\text { Salmonella serovars } \\
(\text { IBT/DMFit) }\end{array}$ & S. aureus $(\mathrm{IBT})$ \\
\hline $70 / 21.1$ & $360 / 124$ & $420 / 288$ & 720 \\
$75 / 23.9$ & $300 / 230$ & $300 / 288$ & 720 \\
$80 / 26.7$ & $300 / 122$ & $300 / 229$ & 420 \\
$85 / 29.4$ & $180 / 86$ & $300 / 79$ & 480 \\
$90 / 32.2$ & $180 / 108$ & $240 / 135$ & 480 \\
$95 / 35.0$ & $120 / 167$ & $240 / 38$ & 480 \\
$100 / 37.8$ & $120 / 67$ & $240 / 87$ & 420 \\
$105 / 40.6$ & $120 / 60$ & $180 / 110$ & 300 \\
$110 / 43.3$ & $180 / 110$ & $180 / 71$ & 360 \\
\hline
\end{tabular}

$a$ The ECT values were determined using an isothermal-based tool (IBT) and the DMFit 1.0 software.

each test temperature, which was defined as the first sampling time, in minutes, at which growth was greater than the IC. For each inoculum species, the log CFU per gram at each sampling time was calculated for each trial. The change in population at each sampling time (relative to starting concentration) for each trial was calculated. The mean change in log CFU per gram and standard deviation were then calculated for each sampling time for the three trials. Using a one-sided $t$ test with a $5 \%$ significance level (9), the first sampling time at which E. coli O157:H7 and Salmonella serovars populations increased by $>0.3 \log$ and $S$. aureus populations increased by $>1.3 \log$ at each test temperature was determined and denoted as the ECT. Using the ECT at each temperature for each organism, an isothermal-based tool (IBT) was developed and used to predict growth for each challenge study (Table 2).

Data from the isothermal studies were also evaluated using the DMFit 1.0 program (J. Baranyi, Institute of Food Research, Norwich Research Park, Norwich NR4 7UA, UK). Sampling time and $\log$ CFU data for each inoculum species and test temperature were entered into DMFit. With established IC, an ECT was interpolated from the resulting DMFit time and fit results (Table 2).
More than $50 \%$ of the ECTs for S. aureus could only be determined by extrapolating beyond the DMFit results, so figures are not included. Once ECTs were established for E. coli $\mathrm{O} 157: \mathrm{H7}$ and Salmonella serovars (IBT and DMFit), a paired $t$ test was used to compare the two data sets.

In order to use the IBT to predict behavior for a pathogen in pork bellies, the temperature profile for a trial (air temperature for external [surface] inoculation or product temperature for internal inoculation) was divided into $2.8^{\circ} \mathrm{C}\left(5^{\circ} \mathrm{F}\right)$ intervals, and the time that the pork bellies were within each interval was determined. In chronological order, the time for which the product was in a given temperature interval was divided by the ECT for a given pathogen for the uppermost temperature in the interval. The resulting value, multiplied by 100 , equaled the percentage of ECT elapsing in the interval. For example, if a product was between 21 and $23.8^{\circ} \mathrm{C}$ for $25 \mathrm{~min}$ and the ECT for S. aureus at $23.8^{\circ} \mathrm{C}$ was $400 \mathrm{~min}$, then the percentage of ECT for that interval would be $6.25=$ $([25 / 400] \times 100)$. With each successive temperature interval during slow cooking, the percentage of ECT in that interval was calculated, along with the cumulative percentage of ECT (see Table 3 for an example). When cumulative percentage of ECT exceeded 100 for any of the pathogens, we concluded that the process was unsafe. If cumulative percentage of ECT did not exceed 100 for any of the pathogens, we concluded that the process was safe.

For comparison, the same product temperature intervals were used in two different applications with the PMP 7.0 model to predict pathogen behavior in the pork bellies. In the first application (denoted as PMP), actual compositional values of the pork bellies were entered: $\mathrm{pH}$ 6.2, percentage of water-phase salt of 3.4, and ingoing nitrite level of $119 \mathrm{ppm}$. A second application (denoted as PMPP) used more conservative percentage waterphase salt and nitrite values: 0.5 and $0.0 \mathrm{ppm}$, respectively. In both applications, the assigned pathogen initial level was $4.0 \mathrm{log}$ $\mathrm{CFU}$, and the level of concern was $0.3 \log \mathrm{CFU}$ higher for Salmonella serovars and E. coli $\mathrm{O} 157: \mathrm{H} 7$, and $1.3 \mathrm{log} \mathrm{CFU}$ higher for $S$. aureus. When aerobic and anaerobic models existed for a pathogen, the more conservative, i.e., more likely to predict growth, aerobic model was chosen. The model was then used to predict an ECT, here defined as the time for pathogen counts to increase to the level of concern. In chronological order, the time in each temperature interval was divided by the established ECT for that temperature and then multiplied by 100 to result in the

TABLE 3. Example of growth predictions for E. coli O157:H7 internally inoculated in cured-pumped pork belly during a 6-h lowhumidity partial-cooking process ${ }^{a}$

\begin{tabular}{|c|c|c|c|c|c|c|c|c|c|c|}
\hline $\begin{array}{c}\text { Temp } \\
\text { interval }\left({ }^{\circ} \mathrm{C}\right)^{b}\end{array}$ & $\begin{array}{c}\text { Time in } \\
\text { interval (min) }\end{array}$ & IBT ECT & $\% \mathrm{ECT}$ & $\begin{array}{c}\% \text { cumulative } \\
\text { ECT }\end{array}$ & PMPP ECT & $\% \mathrm{ECT}$ & $\begin{array}{c}\% \text { cumulative } \\
\text { ECT }\end{array}$ & PMP ECT & $\%$ ECT & $\begin{array}{c}\% \text { cumulative } \\
\text { ECT }\end{array}$ \\
\hline$\sim 5-21.1$ & 62 & 360 & 17.22 & 17.22 & 396 & 15.66 & 15.66 & 918 & 6.75 & 6.75 \\
\hline $21.2-23.9$ & 19 & 300 & 6.33 & 23.56 & 270 & 7.04 & 22.69 & 660 & 2.88 & 9.63 \\
\hline $24.0-26.7$ & 15 & 300 & 5.00 & 28.56 & 198 & 7.58 & 30.27 & 510 & 2.94 & 12.57 \\
\hline $26.8-29.4$ & 13 & 180 & 7.22 & 35.78 & 150 & 8.67 & 38.94 & 420 & 3.10 & 15.67 \\
\hline $29.5-32.2$ & 14 & 180 & 7.78 & 43.56 & 126 & 11.11 & 50.05 & 372 & 3.76 & 19.43 \\
\hline $32.3-35.0$ & 16 & 120 & 13.33 & 56.89 & 114 & 14.04 & 64.08 & 348 & 4.60 & 24.03 \\
\hline $35.1-37.8$ & 19 & 120 & 15.83 & 72.72 & 102 & 18.63 & 82.71 & 348 & 5.46 & 29.49 \\
\hline $37.9-40.6$ & 22 & 120 & 18.33 & 91.06 & 102 & 21.57 & 104.28 & 348 & 6.32 & 35.81 \\
\hline $40.7-43.3$ & 31 & 180 & 17.22 & 108.28 & 102 & 30.39 & 134.67 & 348 & 8.91 & 44.72 \\
\hline Process safe? & & & & No & & & No & & & Yes \\
\hline
\end{tabular}

${ }^{a}$ ECT values were obtained using the isothermal-based tool (IBT), the USDA ARS PMP 7.0 with conservative compositional values entered (PMPP), and the PMP 7.0 with actual product compositional values entered (PMP).

${ }^{b}$ Assigned upper temperature in interval for predictions except when PMPP and PMP ECT reached program limitations. 
TABLE 4. Populations of Escherichia coli O157:H7, Salmonella serovars, and Staphylococcus aureus internally inoculated in curedpumped pork bellies exposed to partial-cooking processes of 6, 12, or $18 \mathrm{~h}$, conducted at high relative humidity (HH) or low relative humidity $(L H)^{a}$

\begin{tabular}{|c|c|c|c|c|c|c|c|c|c|c|c|c|c|}
\hline \multirow[b]{3}{*}{ Process } & \multirow{3}{*}{$\begin{array}{l}\text { Sampling } \\
\text { time (min) }\end{array}$} & \multicolumn{4}{|c|}{ E. coli $\mathrm{O} 157: \mathrm{H} 7$} & \multicolumn{4}{|c|}{ Salmonella serovars } & \multicolumn{4}{|c|}{ S. aureus } \\
\hline & & \multicolumn{2}{|l|}{$\mathrm{HH}$} & \multicolumn{2}{|l|}{$\mathrm{LH}$} & \multicolumn{2}{|l|}{$\mathrm{HH}$} & \multicolumn{2}{|l|}{$\mathrm{LH}$} & \multicolumn{2}{|l|}{$\mathrm{HH}$} & \multicolumn{2}{|l|}{ LH } \\
\hline & & Log CFU/g & $\mathrm{SD}$ & Log CFU/g & $\mathrm{SD}$ & Log CFU/g & SD & Log CFU/g & SD & Log CFU/g & SD & Log CFU/g & $\mathrm{SD}$ \\
\hline \multirow[t]{4}{*}{$6 \mathrm{~h}$} & 0 & 4.60 & 0.15 & 4.57 & 0.15 & 4.23 & 0.14 & 4.20 & 0.14 & 4.23 & 0.20 & 4.30 & 0.22 \\
\hline & 120 & 4.57 & 0.11 & 4.33 & 0.22 & 4.13 & 0.12 & 3.97 & 0.36 & 4.33 & 0.16 & 4.27 & 0.12 \\
\hline & 240 & 4.50 & 0.09 & 4.17 & 0.31 & 4.07 & 0.11 & 3.50 & 0.17 & 4.47 & 0.17 & 4.17 & 0.26 \\
\hline & 360 & 4.23 & 0.22 & 4.13 & 0.24 & 3.53 & 0.38 & 3.63 & 0.36 & 4.60 & 0.36 & 4.03 & 0.18 \\
\hline \multirow[t]{4}{*}{$12 \mathrm{~h}$} & 0 & 4.57 & 0.13 & 4.50 & 0.16 & 4.33 & 0.23 & 4.30 & 0.14 & 4.30 & 0.21 & 4.23 & 0.20 \\
\hline & 360 & 4.43 & 0.10 & 4.33 & 0.31 & 4.00 & 0.16 & 3.80 & 0.41 & 4.30 & 0.24 & 4.23 & 0.30 \\
\hline & 540 & 4.03 & 0.37 & 4.23 & 0.20 & 3.30 & 0.56 & 3.83 & 0.50 & 4.17 & 0.31 & 4.37 & 0.52 \\
\hline & 720 & 4.03 & 0.64 & 4.10 & 0.33 & 3.27 & 0.58 & 3.53 & 0.66 & 3.73 & 0.27 & 3.67 & 0.59 \\
\hline \multirow[t]{4}{*}{$18 \mathrm{~h}$} & 0 & 4.33 & 0.44 & 4.27 & 0.69 & 4.13 & 0.46 & 3.97 & 0.80 & 4.17 & 0.36 & 4.03 & 0.75 \\
\hline & 720 & 4.03 & 0.61 & 3.40 & 1.27 & 3.77 & 0.50 & 2.63 & 1.60 & 4.17 & 0.81 & 3.57 & 1.05 \\
\hline & 900 & 4.33 & 0.46 & 3.53 & 1.25 & 4.10 & 0.77 & 3.10 & 1.47 & 4.60 & 0.41 & 3.40 & 0.59 \\
\hline & 1080 & 3.73 & 0.36 & 3.33 & 1.43 & 3.20 & 0.52 & 3.00 & 1.43 & 4.27 & 1.08 & 3.20 & 0.64 \\
\hline
\end{tabular}

${ }^{a}$ Each $\log$ CFU per gram value is the mean of three trials.

percentage of ECT. A cumulative percentage of ECT was calculated as each temperature interval was analyzed (see Table 3 for example). When this value exceeded 100 for any of the pathogens, the process was determined to be unsafe. If the value never exceeded 100 for any of the pathogens, the process was determined to be safe.

\section{RESULTS AND DISCUSSION}

Values for ECT (Table 2) determined in small-scale isothermal inoculation studies with ground pork ranged from $720 \mathrm{~min}$ at $21^{\circ} \mathrm{C}$ (S. aureus) to $120 \mathrm{~min}$ at $40.6^{\circ} \mathrm{C}(\mathrm{E}$. coli $\mathrm{O} 157: \mathrm{H} 7)$ using the IBT and from $288 \mathrm{~min}$ at $21^{\circ} \mathrm{C}$ to $38 \mathrm{~min}$ at $35^{\circ} \mathrm{C}$ (Salmonella serovars) using the results from DMFit. It must be stressed that ECT values from the IBT were relatively imprecise. More precise values could be obtained and the predictive tool refined as greater numbers of plating times near the ECT are employed and as other pathogen strains are tested. At temperatures for which the IC for pathogen growth was reached or exceeded, the ECT was the sampling time at which this level of growth occurred. If the IC was never exceeded, e.g., $21.1^{\circ} \mathrm{C}$ for $S$. aureus, the ECT used was the final sampling time. The ECT values from the IBT for E. coli O157:H7 and Salmonella serovars are consistent with an earlier study (4) of these pathogens on small or commercial-sized pieces of beef, pork, and chicken products exposed to $22 \pm 2{ }^{\circ} \mathrm{C}$. The ECT values obtained using DMFit were significantly different from those obtained using the IBT $(P=0.011$ and 0.0006 for E. coli O157:H7 and Salmonella serovars, respectively) and clearly would result in a more conservative predictive tool (smaller ECT). These ECTs also did not follow the expected pattern relative to temperature, i.e., steadily decreasing from $21.1^{\circ} \mathrm{C}$ to the optimum growth temperature and then increasing at even higher temperatures; and were therefore not used in evaluating the data from the laboratory pork belly inoculation studies. Additional sample data (more sampling times and pathogen strains) are probably needed to obtain more useful ECT values from DMFit. The partial-cooking processes conducted in the laboratory resulted in a range of time-temperature profiles for pork bellies. In general, the processes were slightly less severe (temperature closer to optimum for growth) than the process actually used by the company supplying the pork bellies. Thus, the pork belly inoculation studies provided a conservative simulation of this company's process. Tables 4 and 5 contain a summary of pathogen populations in internally and externally inoculated pork bellies during the various partial-cooking processes. The results clearly show that no meaningful pathogen growth occurred, relative to time zero values. Thus, it appears that the slow partial-cooking procedures tested are safe for commercial use and scientifically valid critical limits could be selected based on our experimental parameters.

The IBT predicted Salmonella serovars, E. coli O157: $\mathrm{H} 7$, and $S$. aureus growth in the pork belly interior for 10 , 14 , and 5 of 18 trials, respectively. In comparison, PMPP predicted growth for 9, 17, and 9 of 18 trials and PMP predicted growth for 8,6 , and 6 of 18 trials, respectively. The IBT was notably fail-safe, because pathogen growth, relative to time zero, did not occur anytime it was predicted (Tables 4 and 5). The PMPP and PMP were also fail-safe. No pathogen growth occurred in trials for which no growth was predicted by any method. For externally inoculated pork bellies, in which no pathogen growth was also observed relative to time zero, the IBT predicted Salmonella serovars, E. coli O157:H7, and S. aureus growth on the pork belly surface for 3,5 , and 2 of 18 trials, respectively. In comparison, PMPP predicted growth for 2, 9, and 3 of 18 trials, and PMP predicted growth for 2, 1 , and 2 of 18 trials, respectively. The conservative nature of the two PMP 7.0 applications is consistent with that reported for an application of PMP 6.1 (earlier version) in evaluating the likelihood of S. aureus growth in slow-cooked ham (5). Although the PMP and PMPP methods were somewhat less conservative than IBT and thus appear to offer processors 
TABLE 5. Populations of Escherichia coli O157:H7, Salmonella serovars, and Staphylococcus aureus externally inoculated in curedpumped pork bellies exposed to partial-cooking processes of 6, 12, or $18 \mathrm{~h}$, conducted at high relative humidity (HH) or low relative humidity $(L H)^{a}$

\begin{tabular}{|c|c|c|c|c|c|c|c|c|c|c|c|c|c|}
\hline \multirow[b]{3}{*}{ Process } & \multirow{3}{*}{$\begin{array}{l}\text { Sampling } \\
\text { time (min) }\end{array}$} & \multicolumn{4}{|c|}{ E. coli $\mathrm{O} 157: \mathrm{H} 7$} & \multicolumn{4}{|c|}{ Salmonella serovars } & \multicolumn{4}{|c|}{ S. aureus } \\
\hline & & \multicolumn{2}{|l|}{$\mathrm{HH}$} & \multicolumn{2}{|l|}{ LH } & \multicolumn{2}{|l|}{$\mathrm{HH}$} & \multicolumn{2}{|l|}{$\mathrm{LH}$} & \multicolumn{2}{|c|}{$\mathrm{HH}$} & \multicolumn{2}{|l|}{$\mathrm{LH}$} \\
\hline & & Log CFU/g & SD & Log CFU/g & $\mathrm{SD}$ & Log CFU/g & SD & Log CFU/g & SD & Log CFU/g & SD & Log CFU/g & SD \\
\hline \multirow[t]{4}{*}{$6 \mathrm{~h}$} & 0 & 4.73 & 0.11 & 4.77 & 0.05 & 4.33 & 0.09 & 4.23 & 0.08 & 4.60 & 0.14 & 4.47 & 0.10 \\
\hline & 120 & 4.53 & 0.08 & 4.20 & 0.24 & 4.23 & 0.20 & 3.63 & 0.30 & 4.53 & 0.10 & 4.47 & 0.08 \\
\hline & 240 & 4.47 & 0.07 & 2.87 & 0.29 & 3.97 & 0.09 & 2.17 & 0.46 & 4.63 & 0.09 & 3.87 & 0.37 \\
\hline & 360 & 4.00 & 0.19 & 2.50 & 0.14 & 3.43 & 0.20 & 1.63 & 0.41 & 4.83 & 0.25 & 3.73 & 0.18 \\
\hline \multirow[t]{4}{*}{$12 \mathrm{~h}$} & 0 & 4.63 & 0.08 & 4.67 & 0.04 & 4.40 & 0.05 & 4.43 & 0.03 & 4.30 & 0.27 & 4.50 & 0.05 \\
\hline & 360 & 3.83 & 0.51 & 3.00 & 0.27 & 3.00 & 0.52 & 2.17 & 0.42 & 4.47 & 0.13 & 3.77 & 0.18 \\
\hline & 540 & 2.90 & 0.63 & 2.20 & 0.62 & 2.27 & 0.58 & 1.60 & 0.43 & 4.13 & 0.31 & 3.63 & 0.45 \\
\hline & 720 & 2.33 & 0.83 & 2.53 & 0.70 & 1.60 & 0.49 & 1.63 & 1.00 & 3.80 & 0.76 & 3.47 & 0.60 \\
\hline \multirow[t]{4}{*}{$18 \mathrm{~h}$} & 0 & 3.80 & 0.64 & 4.10 & 0.36 & 4.00 & 0.61 & 4.27 & 0.39 & 4.20 & 0.70 & 4.43 & 0.40 \\
\hline & 720 & 2.77 & 0.89 & 2.10 & 0.90 & 2.23 & 0.25 & 1.47 & 0.71 & 4.10 & 0.68 & 3.50 & 0.57 \\
\hline & 900 & 1.73 & 1.11 & 2.97 & 0.93 & 0.80 & 0.50 & 2.63 & 0.95 & 3.87 & 0.48 & 4.20 & 0.51 \\
\hline & 1080 & 1.30 & 1.07 & 2.30 & 1.13 & 0.60 & 0.40 & 2.10 & 0.93 & 3.27 & 0.93 & 4.23 & 0.59 \\
\hline
\end{tabular}

${ }^{a}$ Each $\log$ CFU per gram value is the mean of three trials.

more leeway, their use may be questioned because their results are based on studies using bacteriological media and not an analogous food matrix.

The IBT developed in this study for the evaluation of non-isothermal partial-cooking processes is a straightforward, relatively simple approach. To our knowledge, there are no other published accounts of this type of pathogen growth prediction tool. More complex models have been studied by others for predicting pathogen growth or survival under non-isothermal conditions. For example, Hassani et al. (3) developed a predictive model for Listeria monocytogenes in laboratory media heated at different rates. Their model was also built using data obtained in isothermal experiments, but it underestimated $L$. monocytogenes thermotolerance. The challenges of predicting pathogen growth in meat systems, particularly the effect of different levels of indigenous competing bacteria, were reviewed by Shimoni and Labuza (8).

The IBT predictions in the present study were conservative. The conservative nature of the predictions may result from limitations such as using the $21.1^{\circ} \mathrm{C}$ ECT value for temperatures $<21.1^{\circ} \mathrm{C}$ ("worst-case" scenario based on the temperature range of concern described in USDA cooking guidance (13)), use of the ECT value for $43.3^{\circ} \mathrm{C}$ at temperatures $>43.3^{\circ} \mathrm{C}$, and the absence of potentially inhibitory compounds such as salt, cure, and spices in the ground pork used in the isothermal studies. Addressing these limitations could decrease the conservative nature of the IBT. On the other hand, increasing the fat level in ground pork used for isothermal studies could be expected to increase ECT values, as would using pork with high levels of competing bacteria $(1,10,15)$. The effect of competing microflora is especially notable for $S$. aureus (6), and future studies should address this issue. Overall, the risk of using a conservative predictive tool, i.e., discarding product that is actually safe, is preferable to the risk of unknowingly selling unsafe product as a result of using a less conser- vative tool or model. For small and very small pork processors, the HACCP system may be a disproportionate financial burden (11), so the benefits of a simple conservative predictive tool for use in setting scientifically valid critical limits may outweigh the cost of the tool's conservative nature. The IBT also is quite versatile, having been shown to be a conservative predictor of pathogen growth during cooling of hot-boned pork products (2).

In summary, our results show that slow partial cooking of cured-pumped pork bellies, in conditions at least as severe as employed in the present study, is safe. The IBT appears to be an effective, albeit very conservative, tool for evaluating the safety of slow partial-cooking processes for pork. Similarly, using an application of PMP 7.0 involving conservative values for compositional characteristics would also be an effective process evaluation tool. Critical limits for slow partial cooking of bacon could be safely based on IBT predictions and should be considered scientifically valid.

\section{ACKNOWLEDGMENTS}

This project was supported by a grant from the U.S. Department of Agriculture Cooperative State Research, Education, and Extension Service. We thank Don Schaffner for his anonymous contributions as a reviewer and for his subsequent advice on the use of the Baranyi model and the calculation of the ECTs. We gratefully acknowledge the assistance of Ryan Algino, Amy Haen, Mike De Vita, and Rishi Wadhera.

\section{REFERENCES}

1. Berry, E. D., and M. Koohmaraie. 2001. Effect of different levels of beef bacterial microflora on the growth and survival of Escherichia coli $\mathrm{O} 157: \mathrm{H7}$ on beef carcass tissue. J. Food Prot. 64:11381144.

2. Fanslau, M. A., G. M. Burnham, and S. C. Ingham. 2005. Evaluating the use of predictive models for critical limit validation in raw pork products. Proceedings of the 51st International Congress of Meat Science and Technology, Baltimore, Md., 7 to 12 August 2005.

3. Hassani, M., P. Mañas, J. Raso, S. Condón, and R. Pagán. 2004. 
Predicting heat inactivation of Listeria monocytogenes under nonisothermal treatments. J. Food Prot. 68:736-743.

4. Ingham, S. C., J. A. Losinski, K. L. Becker, and D. R. Buege. 2004. Growth of Escherichia coli O157:H7 and Salmonella serovars on raw beef, pork, chicken, bratwurst and cured corned beef: implications for HACCP plan critical limits. J. Food Safety 24:246-256.

5. Ingham, S. C., J. A. Losinski, B. K. Dropp, L. L. Vivio, and D. R. Buege. 2004. Evaluation of Staphylococcus aureus growth potential in ham during a slow-cooking process: use of predictions derived from the U.S. Department of Agriculture Pathogen Modeling Program 6.1 predictive model and an inoculation study. J. Food Prot. 67:1512-1516.

6. International Commission on Microbiological Specifications for Foods of the International Union of Biological Societies. 1996. Microorganisms in food 5. Characteristics of microbial pathogens. Blackie Academic \& Professional, London.

7. Jay, J. M. 1992. Modern food microbiology, 4th ed. Chapman \& Hall, New York.

8. Shimoni, E., and T. P. Labuza. 2000. Modeling pathogen growth in meat products: future challenges. Trends Food Sci. Technol. 11:394402.
9. Snedecor, G. W., and W. G. Cochran. 1989. Statistical methods. Iowa State University Press, Ames, Iowa.

10. Tamplin, M. L. 2002. Growth of Escherichia coli O157:H7 in raw ground beef stored at $10^{\circ} \mathrm{C}$ and the influence of competitive bacterial flora, strain variation, and fat level. J. Food Prot. 65:1535-1540.

11. Taylor, E. 2000. HACCP in small companies: benefit or burden? Food Control 12:217-222.

12. U.S. Department of Agriculture. 1996. Pathogen reduction; hazard analysis and critical control point (HACCP) systems: final rule. Fed. Regist. 61:38805-38855.

13. U.S. Department of Agriculture Food Safety and Inspection Service. 1999. Compliance guidelines for meeting lethality performance standards for certain meat and poultry products, Appendix A. Available at: http://www.fsis.usda.gov/oa/fr/95033f-a.htm. Accessed 24 May 2005.

14. U.S. Department of Agriculture Food Safety and Inspection Service. 2005. Use of microbial pathogen computer modeling in HACCP plans, FSIS Notice 25-05. Available at: http://www.fsis.usda.gov/ regulations/notice_25-05/default.asp. Accessed 24 May 2005.

15. Vold, L., A. Holck, Y. Wasteson, and H. Nissen. 2000. High levels of background flora inhibits growth of Escherichia coli O157:H7 in ground beef. Int. J. Food Microbiol. 56:219-225. 